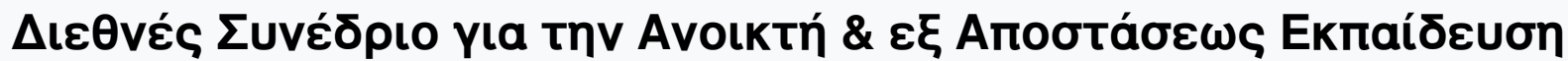

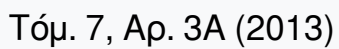

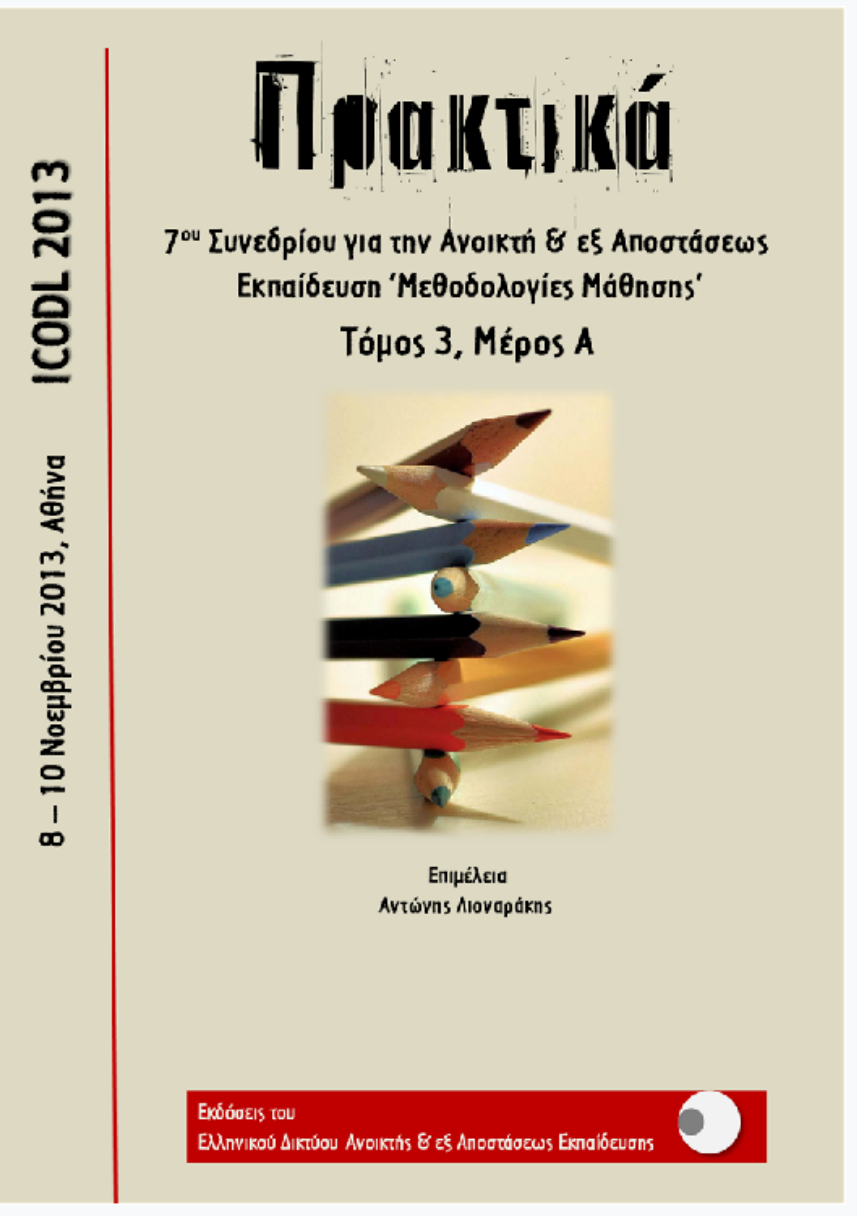

Enhancing Learning Management Systems (LMS) with the use of Web Technologies

Marigianna Skouradaki, Michail Kalogiannakis, Dimitrios Plexousakis

doi: $10.12681 /$ icodl. 610 


\title{
Enhancing Learning Management Systems (LMS) with the use of Web Technologies
}

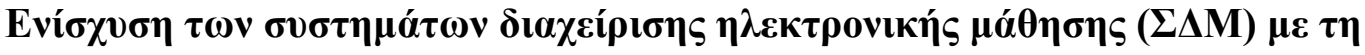 $\chi \rho \eta ́ \sigma \eta \tau \varepsilon \chi v o \lambda o \gamma \iota \omega ́ v \pi \alpha \gamma \kappa o ́ \sigma \mu t o v ~ เ \sigma \tau о v ́$}

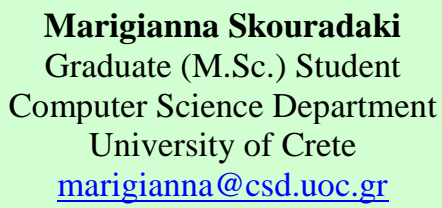

\author{
Michail Kalogiannakis \\ Lecturer \\ Faculty of Education, \\ Department of Preschool \\ Education, \\ University of Crete \\ mkalogian@edc.uoc.gr
}

\author{
Dimitrios Plexousakis \\ Affiliated Researcher to \\ ICS-FORTH \\ Professor of Computer \\ Science \\ University of Crete \\ dp@ics.forth.gr
}

\begin{abstract}
By using Learning Management Systems (LMS), educators are able to create numerous resources expressed by various technological tools (HTML pages, quizzes, forums, wikis etc.). In this manner, the student is supported throughout the educational process. The students in their turn interact with these resources, by experiencing an enriched learning process. However, the LMSs do not provide adaptivity or guidance to the students' choices. As a result the students use their own criteria to choose between large collections of resources. This usually leads to frustration, and wrong choices, as the students' abilities are not taken into serious consideration.

This paper focuses on Information and Communication Technologies (ICT) in Education. More specifically, it proposes a way to enhance the Moodle LMS's functionality by providing more adaptivity. Our ultimate goal is to improve the situation described above. For this purpose, we have designed a user-friendly interface through which the educator can dynamically develop a knowledge base (in the form of an Ontology) of the learning objectives of the e-course's resources.

Although the Moodle LMS already supports a mechanism for tagging its resources, this particular proposal extends this functionality, by adding "hierarchical" information. That means that by using the interface the educator adds to the system the knowledge that the learning objectives of «Resource 1», are prerequisite knowledge for understanding the learning objectives of «Resource $2 »$. By offering that knowledge to the system, an agent observes the student's actions and makes personalized suggestions, concerning navigation, or further actions. Finally, the proposed approach can be extended to different LMSs as Web Services were used for the creation of the above functionalities. By implementing the above features, we achieve the enhancement and extension of Moodle LMS's adaptive functionality.
\end{abstract}

Keywords: e-learning, Adaptive Learning, Learning Management Systems

\section{Пврі́ $\eta \psi \eta$}

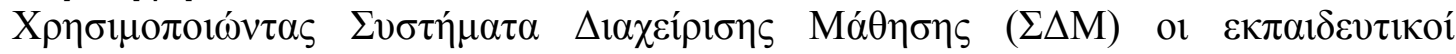

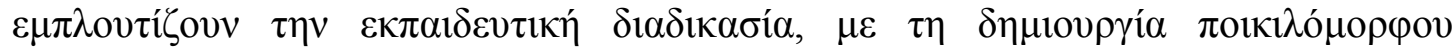

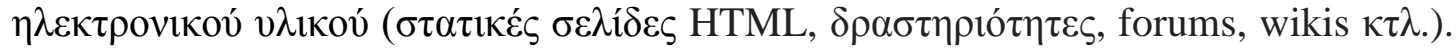




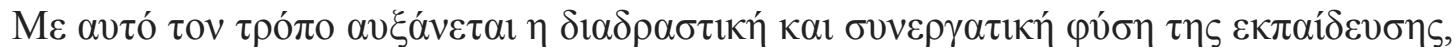

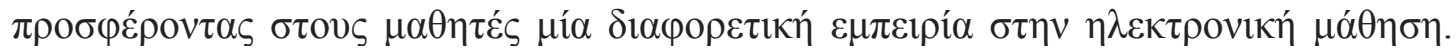

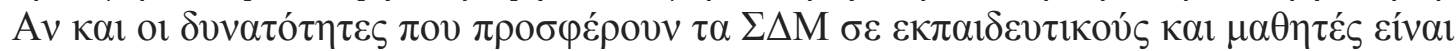

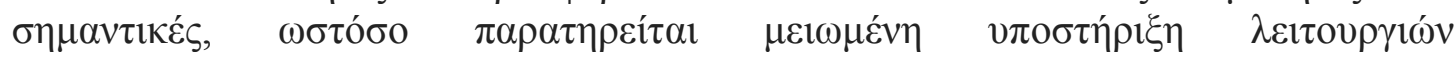

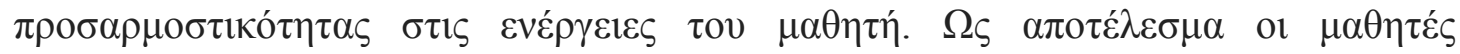

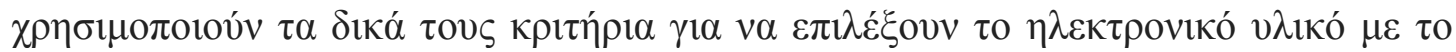

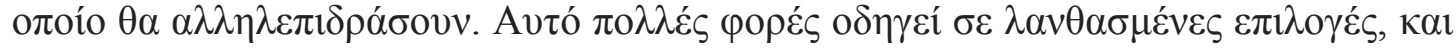

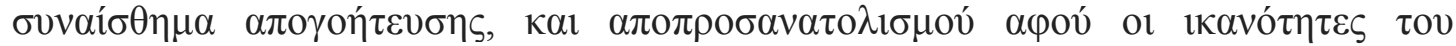

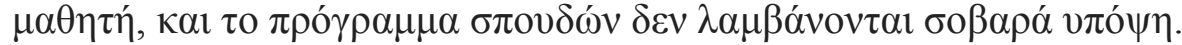

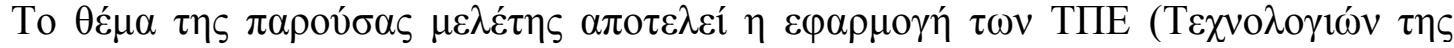

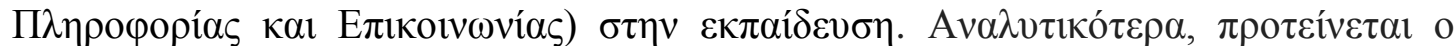

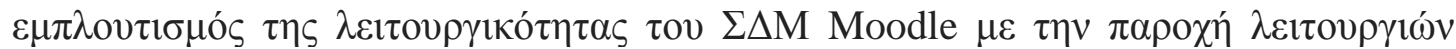

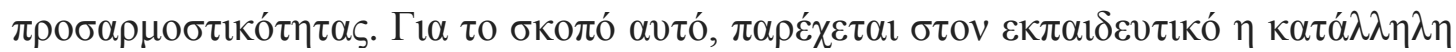

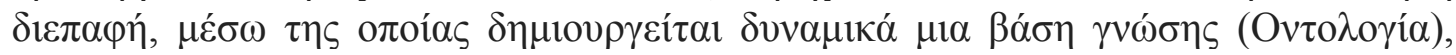

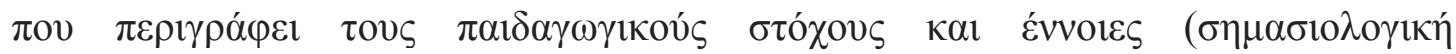

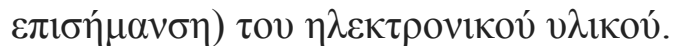

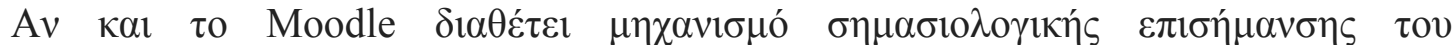

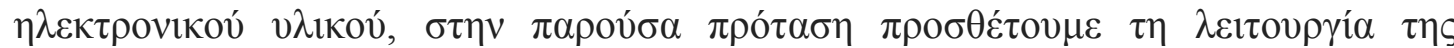

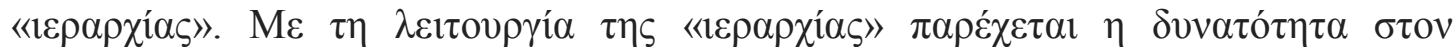

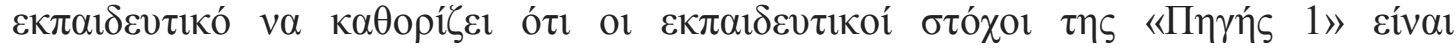

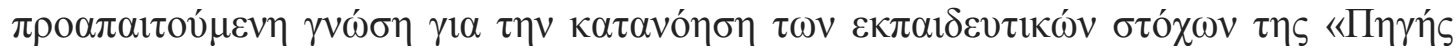

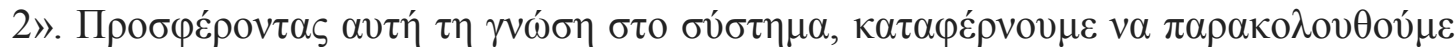

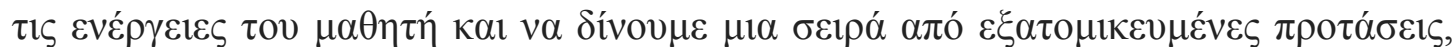

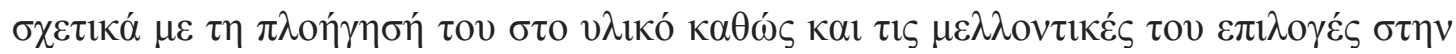

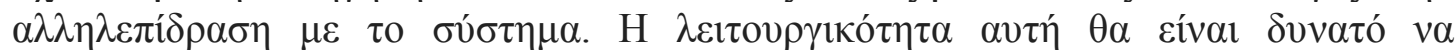

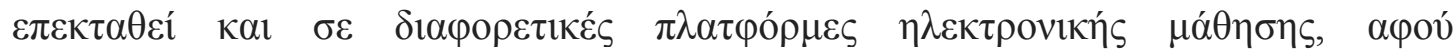

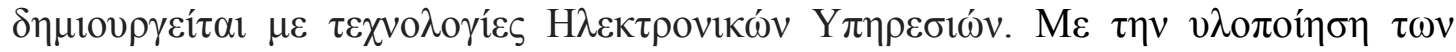

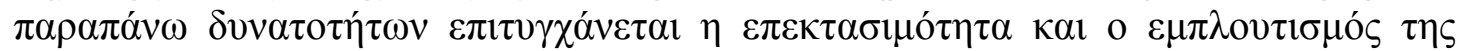

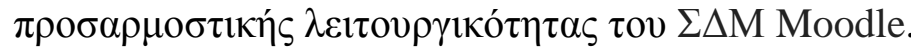

\section{Introduction}

During the last decades technology has followed a fast evolution line by changing in terms of complexity and variety (Caladine, 2008). The $21^{\text {st }}$ century, is characterized by the widespread and global adaptation of Internet based technologies. At the same time, Educational Technologies are gaining an equally noteworthy role in the field (Caladine, 2008). Current Educational Technologies have emerged from the evolution of the Web as a "system" of information sharing, interoperability, user-centered design, and collaboration. They are also characterized by an increased quantity of material produced by students (Taylor, 2001).

Despite the wide variety of technological options that can be applied in the educational process (Caladine, 2008) most technological applications follow a unique model for interacting with their users. The model assumes similar user abilities, preferences and characteristics, by expressing the notion of «one-size fits them all» (Despotovic-Zrakic et al., 2012; Annan, 2013). In an era where modern learning theories embrace heterogeneous classrooms, technology should also follow towards the same direction. However it is claimed that current Learning Management Systems (LMSs) lack of adaptive features (Despotovic-Zrakic et al., 2012).

With respect to this need, this paper focuses to the development of a complete software solution of a learner-centric environment. The system will be using the 
following technologies: Learning Management Systems (Moodle), E-learning 2.0, and Adaptive Hypermedia. For purposes of demonstration, the environment uses the learning material of Greek Secondary School Mathematics $\left(1^{\text {st }}\right.$ grade) as it is presented in the digital book of Mathematics published from the Hellenic Ministry of Education and Religious Affairs, Culture and Sports. The proposed solution expands the digital book, by adding interactive and collaborative elements (E-learning 2.0). The environment also uses adaptive navigation features by implementing new functionalities for Moodle LMS.

This paper aims to describe the development of an environment, by analyzing the corresponding theoretical framework, and describing the proposed features with respect to that. Thus it is organized as follows: Section 1 is an overview of the emerging learning theories, and technological trends that were used for developing the environment; Section 2 explains the decisions that were made based on this theoretical framework; Section 3 is an overview of the proposed environment that is under construction; Lastly, Section 4 summarizes the environment's key points and outlines our intentions for future work.

\section{Theoretical framework}

This chapter describes the technologies that were chosen for implementing the environment, with respect to their impact in e-learning. Moreover, the analysis of the tools' characteristics will lead the reader to a holistic point of view of the decisions that were taken, during the environment's implementation. After all, it is necessary to comprehend the tools' features in order to use them in a qualitative way. The described technologies are Web 2.0 / E-Learning 2.0 technologies, Learning Management Systems (LMS), and Adaptive Hypermedia.

\subsection{Web 2.0 and E-learning 2.0}

The term "Web 2.0" is closely associated to Tim O' Reilly (2005) who was the first to introduce it as:

The era when people have come to realize that it's not the software that enables the web that matters as much as the services that are delivered over the web.

And later on (2009) he suggested that:

Web 2.0 is all about harnessing collective intelligence (p. 3).

Although the term "Web 2.0" is used widely, it is still difficult to find a unique definition that describes it with precision (Bartolome, 2008; Exter et al., 2012). However, in order to help the reader conceptualize what Web 2.0 is, O'Reilly (2005) lists a number of tools that comprise Web 2.0 such as: Google AdSense, Wikipedia, Blogging, Web Services, wikis, tagging («folksonomy») etc.

In general Web 2.0 is considered to be a "second generation" of the World Wide Web technologies and applications, where more creative learning approaches, embedded in computer games, 3D simulations, virtual realities and other immersive environments such as multimedia applications, visual and audio tools, immersive environments and serious games, and mobile learning devices address different sensory channels, supply more engaging learning opportunities and support individualized learning opportunities with the help of synchronous or asynchronous tools (Caladine, 2008; Exter et al., 2012). The applicability of Web 2.0 tools in the educational process has lead to the creation of "e-learning 2.0" (Bartolome, 2008; Exter et al., 2012). The term "e-learning 2.0" is also used to describe the combination of Web 2.0 tools with the 
Semantic Web (or Web 3.0) (Caladine, 2008; Chaka, 2010), which means that along with Web 2.0 tools in education we should use:

a common framework that allows data to be shared and reused across

applications, enterprise and community boundaries (W3C, 2007).

In this paper the term e-learning 2.0 is used to describe the combination of Web 2.0 and Semantic Web as it is considered to be more representative of the current situation.

The positive impact of e-learning 2.0 in education is multidimensional. Ohler (2008) and Redecker et al. (2010) recognize technological, pedagogical and organizational innovations that have originated from the use of social computing. Therefore, eLearning 2.0 elements were chosen for the expression of the learning material that is presented in the research. As mentioned earlier, the learning material presented in this project is based on the Greek Secondary School Mathematics course, of the $1^{\text {st }}$,grade. This material was selected for demonstration purposes. That means that future use of the projects' ideas and functionalities might select to present different educational content.

The content that we used is presented in the digital book of Mathematics published from the Hellenic Ministry of Education and Religious Affairs, Culture and Sports.

This choice of content was done as the Ministry's printed book is considered to present approved educational material of the highest quality. Despite the high quality of the printed book's content, the digital books presentation leaves space for improvements. Althoughthe enriched edition of the digital book offers some virtual experiments, the book is mostly a faithful representation of the school book. It lacks interactive, collaborative features and e-learning 2.0 elements. We therefore considered it necessary to adapt the book's content differently with respect to the new learning theories and technologies. Harper et al. (2008) argue that learning material should be created with respect to the emerging learning theories for an effective and efficient use. Behaviorist learning theory, cognitive learning theory, and constructivist learning theories are the theories that conquer the computer-based instruction. Instructional design models give helpful guidelines for creating learning material that comprises with the learning theories (Harper et al., 2008). As research progresses, new theories that should be used are emerging. A recent example is connectivist theory, which is needed for the emerging age of distributed and network learning (Anderson, 2004).

Gagne et al. (1991) have proposed one of the most widely known models for instructional design. IEEE.org suggests that this model should be followed when developing learning material. The model is expressed in terms of nine types of instructional events. The events are shown briefly in Picture 1:

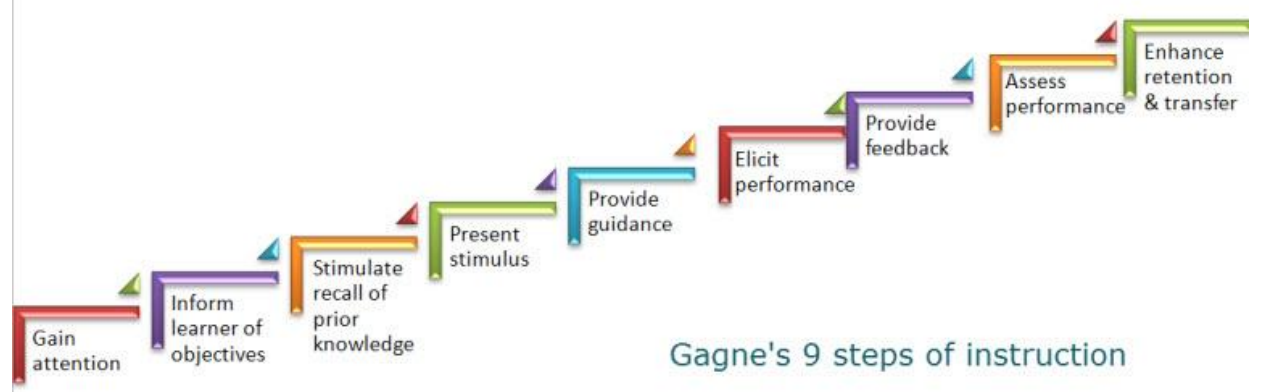

Picture 1: Gagne's 9 steps of instruction (La Trobe University, n.d.) 
Below we explain how these events were applied to the development of the material:

a) Gain the learner's attention: e-learning 2.0 tools natively raise the learner's interest. It is proven that young people are highly attracted in using them (Cummins, Brown, \& Sayers, 2007; Warschauer, 2011).

b) Inform the learner of the lesson objective: This principle was initially followed to the creation of the material that was used for the printed-book.

c) Stimulate recall of prior knowledge: This principle was initially followed to the creation of the material that was used for the printed-book. We enhance this principle with the adaptive navigation features that are described later in this paper.

d) Present stimuli with distinctive features to aid in perception: Multimedia and interactive activities will be used in the environment. The usage of multimedia lays to the fact that they enable the interactive potential of the computer to the presentation impact of images, sound and animations (Dieter, 2006). More particularly, their nature allows the usage of more than one human sense during the interaction, which is educationally valuable (Reddi \& Mishra, 2003). Additionally images and other multimedia elements on a textbased screen can relieve the eye, thus making the experience more pleasant, enforce the engagement, and provide better concept representation (Reddi \& Mishra, 2003; Cheng, 2010).

e) Guide learning to promote semantic encoding: This principle was initially followed to the creation of the material that was used for the printed-book.

f) Elicit performance,

g) Provide informative feedback,

h) Assess performance,

Interactive elements such as quizzes and collaborative activities help to following the principles $\mathrm{f}, \mathrm{g}$ and $\mathrm{h}$. We also enhance the environment to these directions with the adaptive features and feedback enhancement that are described later in this paper.

i) Enhance retention and learning transfer: This principle was initially followed to the creation of the material that was used for the printed-book. We enhance this principle with the adaptive navigation features that are described later in this paper.

Finally, Dick et al. (2001) highlight the importance of evaluation after the development of the material. For this reason we have been continuously communicating with educators of mathematics of the «Experimental Secondary School of Heraklion» for over viewing and evaluating the e-learning material.

\subsection{LMS overview}

The LMS category includes platforms that are met by a variety of names, including virtual learning environments, Course Management Systems (CMS), and collaborative learning environments. In this paper the term LMS is preferred as CMS might also mean Content Management System. The primary purpose of LMSs was to enable students to interact with content, fellow students, and faculty through a unique website. Nowadays, LMS's have extended their functionality by transforming themselves into powerful tools (Caladine, 2008). More particularly, Mohawk College (2009) suggested that an 
LMS can be broadly described as a web-accessible platform for the 'anytime' delivery, tracking and management of education and training.

LMSs are essentially software running on dedicated hardware (p. 5).

Currently, there are many LMSs available: Blackboard ${ }^{\mathrm{TM}}$, FirstClass ${ }^{\mathrm{TM}}$, Moodle $^{\mathrm{TM}}$, Lotus Learning Space ${ }^{\mathrm{TM}}$ (Naidu, 2003) ATutor $^{\mathrm{TM}}$, Dokeos ${ }^{\text {TM }}$, Olat ${ }^{\mathrm{TM}}$ (Aydin \& Tirkes, 2010), Elgg ${ }^{\mathrm{TM}}$ some of which are commercial while others are open source. Each one of these LMS platforms varies in capabilities and features. In general, LMS cannot be considered as a single, autonomous technology, but as a collection of technological tools, with various roles in teaching and learning (Caladine, 2008). So a LMS is a convenient tool to use when trying to combine and integrate technologies. American Society of Training and Development (ASTD) (2009), indicates that a robust LMS should have at least the following features:

- Centralize and automate administration;

- Offer self-service and self-guided services (such as learner self-registration for courses);

- Rapidly assemble and deliver learning content;

- Consolidate training initiatives on a scalable Web-based platform;

- Support portability and standards, such as sharable content object reference model ( $\underline{\mathrm{SCORM}})$; instructional management system ( $\underline{\mathrm{IMS}})$, learning object metadata ( $\underline{\mathrm{LOM}})$, and

- Personalize content and enable knowledge reuse.

And although the above are minimum requirements, Caladine(2008) and Monarch Media Inc. (2010) recognize that current enterprise-grade LMS solutions include more functionalities that usually include:

- Content management features that provide control over the storage, aggregation, retrieval, and delivery of learning materials;

- Rebranding and customization options;

- User management tools allowing administrators to categorize users and assign them to roles and groups, and match learners or groups of learners to courses;

- Features of assessment, grading and tracking;

- Email, wikis, discussion boards, chat and other collaboration tools;

- Reporting and analytics about system and course usage, learner progress, assessment results, and more; and

- Security features limiting access to authorized people and roles.

Overviewing the above, it is easy to conclude that LMSs make learning and teaching quicker, easier and less expensive, by providing a learner - centered environment. What is more, LMSs provide the educator a wide range of useful functionalities. Thus, they are considered an extremely efficient tool for creating large-scale systems as they reduce significantly the required time and costs (Naidu, 2003). For the development of our system we have chosen the Moodle LMS. Moodle is Open Source, and it comprises a large community of users and developers. Open Source products, make it possible to third party developers to change or extend their code. By that way, new functionality is added to the product, with the hope that it will make a valuable contribution to Moodle community.

With respect to this choice the e-learning material is created and presented through the Moodle LMS. The available e-learning material is brought to the student in the form of large collections of resources. This non-linear format of information representation is considered a basic rationale in e-learning. That is caused by the fact that learners are able to construct their own path on learning, by exploring and 
discovering information according to their needs and preferences (Chen, 2002). However this freedom also has a negative impact in learning, as flexibility also increases complexity (Ellis \& Kurniawan, 2000). Accessing information in the students' preferred way, might not take into consideration their learning styles and levels of knowledge. This leads to disorientation, and disruption to better outcomes. In order to overcome this difficulty, this paper proposes an extension of Moodle LMS's functionality (plug-in), which is described in sub-section "2.3 Adaptive Hypermedia'. The main purpose of the new functionality would be to make personalized suggestions to the students, by providing a form of unstructured guidance.

\subsection{Adaptive Hypermedia}

It is commonly accepted, that a classroom consists of students with different learning styles, abilities, characteristics and needs. Taking this fact into consideration, we respectively expect an LMS system to be used by users with various characteristics. However, most LMSs are still following the «one-size-fits-all» model which preassumes a unique model of users. This lack of adaptivity is not appropriate for such a heterogeneous environment as a classroom (Annan, 2013; Despotovic-Zrakic et al., 2012). Therefore adaptive functionality was set as a primary goal for this project. The LMSs to support adaptive functionalities are considered to comprise the next generation of LMSs (Despotovic-Zrakic et al., 2012).

More particularly according to (Paramythis \& Loidl-Reisigner, 2004), an e-learning system is considered to be adaptive if it is capable of:

Monitoring the activities of its users; interpreting these on the basis of domain-specific models; inferring user requirements and preferences out of the interpreted activities, appropriately representing these in associated models; and, finally, acting upon the available knowledge on its users and the subject matter at hand, to dynamically facilitate the learning process. (p.182).

Annan (2013) recognizes two techniques an adaptive web based system might use: adaptive presentation and adaptive navigation. In adaptive presentation the system adapts the presentation of information to the user's characteristics and preferences. For example, extra details might be hidden from novice users, or information can be presented on different with different text size or media types. In the case of adaptive navigation the system tends to guide the user into exploring the required information. This means that the functionalities of enabling, disabling, showing, hiding, annotating or removing links are applied when it is considered appropriate according to the user's activities and features.

At this point it is important to clarify that Adaptive Hypermedia is not a unique separate category of e-learning tools. On the contrary, it is a set of suggested techniques that would increase existing tools' usability. As mentioned above these techniques are supposed to comprise the next generation of e-learning tools, therefore it is crucial to keep adaptive principles in mind when building an e-learning environment. For this particular solution we have focused on adaptive navigation. As mentioned above, non-linear access to information disorients the student. Thus it is considered essential to create an environment that will help the student focus on their goals.

The adaptive navigation plan that we propose in this paper, is based on resource semantics. In this paper, semantics are the keywords that characterize a learning resource. Consequently, semantics of an e-learning resource might be the concept it 
describes, the learning-objective that it underpins, its level of difficulty, etc. So by using an interface, the educator makes a visual hierarchy of the semantics that are presented on a particular Moodle e-course. This creates a knowledge base (Ontology) of the semantics that take part in an e-course, as well as the semantics that connect the resources between each other. By having this knowledge, the system can export valuable conclusions. For example, it can conclude that learning objectives for "Resource 1" are prerequisite for understanding the learning objectives of "Resource 2'. This in a real life example could apply as: for understanding «Multiplication», the student should have first gained the knowledge for "Addition"'.

By storing this knowledge, the system, can provide a semi-structured navigation environment, based on the e-course's semantics. Moreover, by tracking the student's actions, the system can provide personalized suggestions, for the student's next choices in the environment. For example, if a student achieves a very low score on a quiz, then the system would make a set of suggestions for further studying, studying an easier subject, discussing it with their peers in a forum, retrying the exercise, etc.

The next chapter provides a detailed overview of the system's features and functionalities, in order to help the reader conceptualize better its value.

\section{Overview of the Environment}

\subsection{Designing the features}

The implementation of the environment described above has started and it is now in a beta edition. This section describes the work that is done, and provides some screenshots of the system.

Picture 2 shows the way with which the material is presented to the user as soon as s/he logs in Moodle LMS.

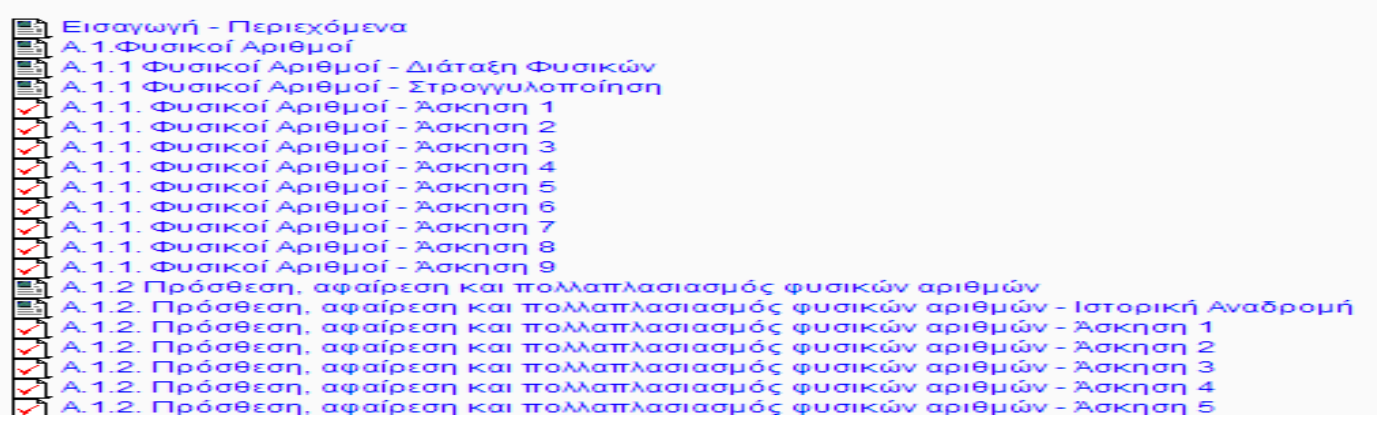

Picture 2: Presentation of Moodle environment's Resources

The resources that our system currently offers are: static HTML pages, interactive exercises (quiz), and forum sections. However, the educator is able to create resources of any type that Moodle supports, as presented on Picture 3. 

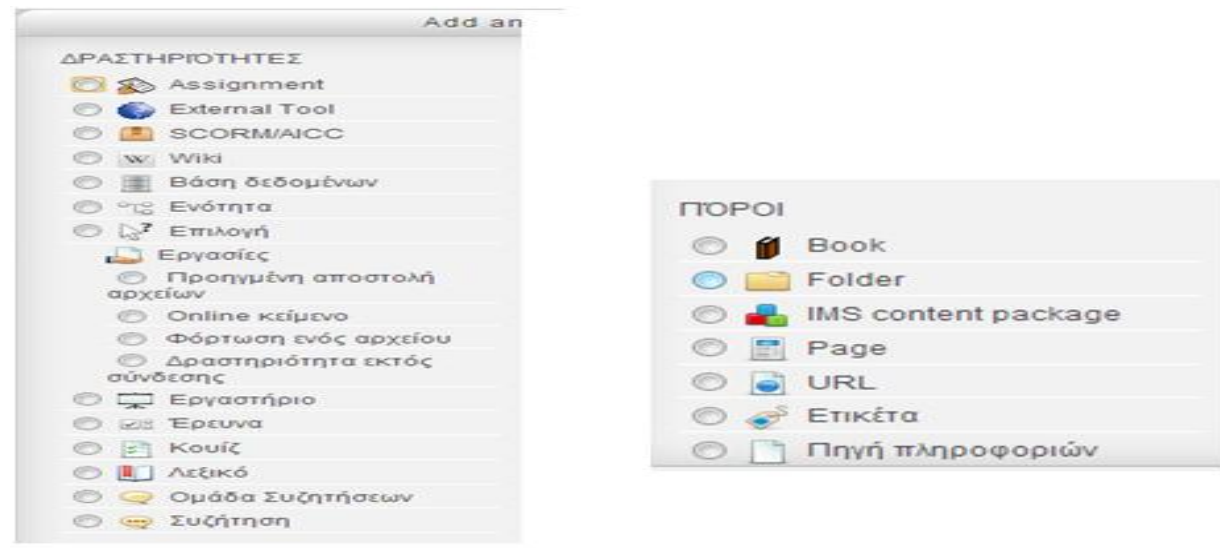

Picture 3: Moodle supported resource types

As explained above, Moodle provides an unstructured, non-linear way of navigation that might disorient the student. With respect to that we have designed a set of functionalities that will enhance the environment towards an adaptive, learnercentered direction. More particularly, at the end of this project the system will help the student in the following ways:

a) Adaptive feedback: The system will make suggestions according to the student's performance, and the exercise's semantics. For example, if the student achieves low, the system will recommend to: revise the learning objective's theory, study more basic learning objectives, practice on easier exercises, and discuss the problem with their classmates. On the contrary, in the case of very high performance, the system will suggest, helping their classmates on the forum, study resources on more difficult learning objectives, and study on extra-curriculum resources.

b) Completion Tracking: Provided a good student' performance, the system will unhide resources of more difficult learning objectives. Although the student will still be able to access the environment in a non-linear way, there will be some constraints on the resources that the student can access. That way, we let the student discover and take the lead on their learning, by guiding them to study learning objectives that are close to their knowledge levels.

c) Dynamic Navigation: The student will be able to navigate through the exercises by choosing the difficulty level (easy, medium, hard).

A delineation of the above activities' flow is presented in the following images (Picture 4, Picture 5): 


\section{Adaptive Feedback}

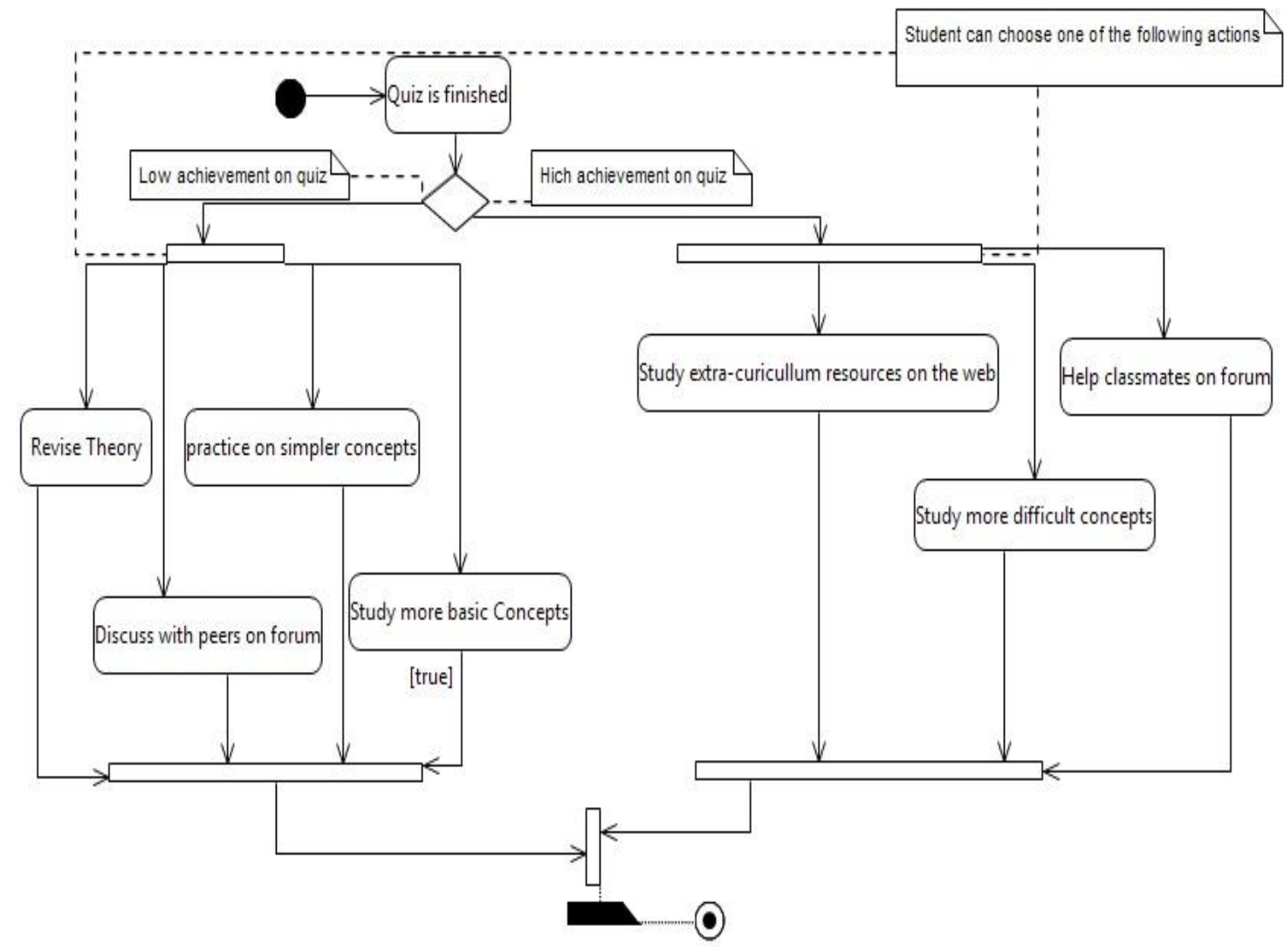

Picture 4: Adaptive Feedback

Dynamic Navigation with Completion tracking

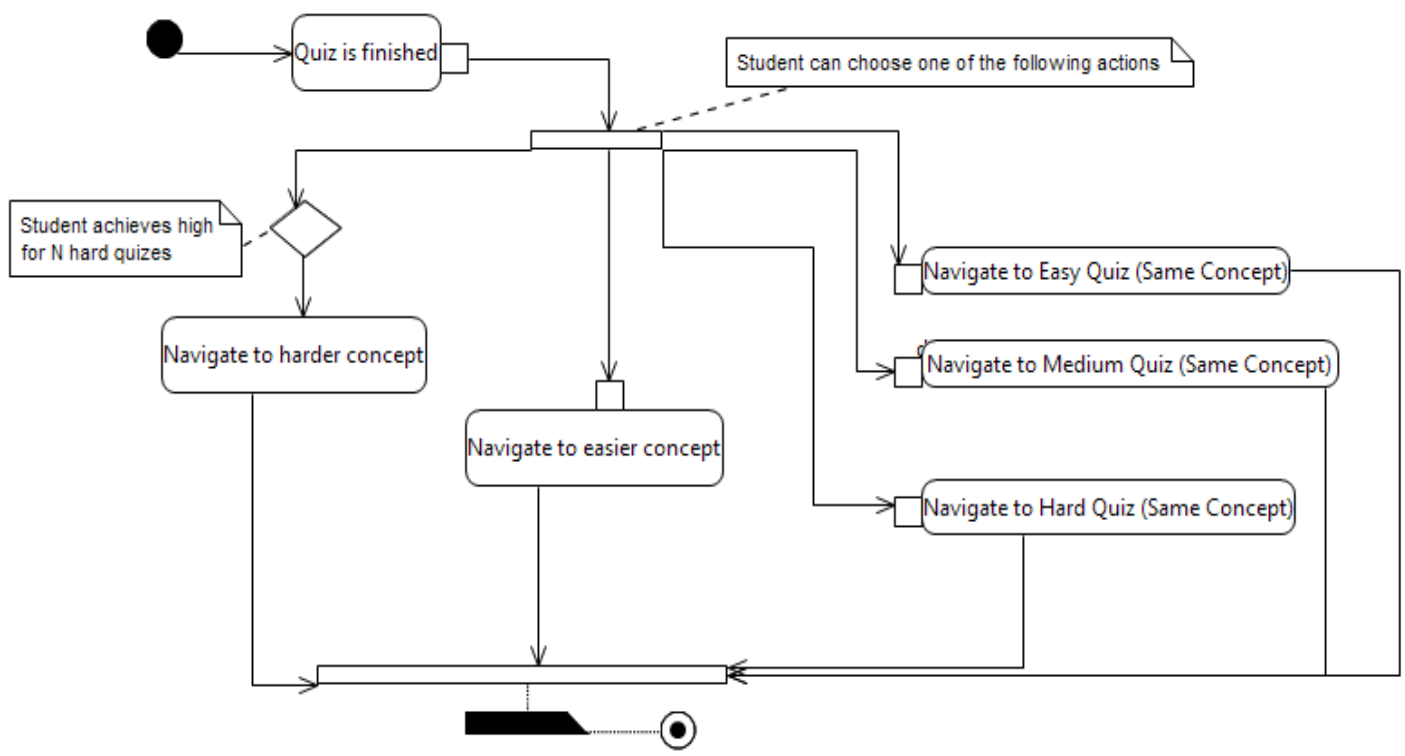

Picture 5: Dynamic Navigation \& Completion Tracking 


\subsection{Creating the knowledge base}

In order to implement the features described above, the educator should follow a set of activities that will add to the system the required knowledge. That is because the system needs to know the semantics of each resource, before making any decisions. The interface on which the educator inserts this knowledge is based on an existing Moodle plug-in that was presented by Elmadani et al. (2012) in the $1^{\text {st }}$ Moodle Conference on 2012. So by expanding this plug-in we enable the educator to create a knowledge base that describes the resources' semantics, and then, the system uses this knowledge base in order to make adaptive decisions and suggestions. In the rest of this section we present the usage of the plug-in, within which the educator builds the knowledge base.

Picture 6 presents the plug-in's main menu. The first step for the educator is to choose «Edit Concept Tagging Hierarchy Tree» from the plug-in's menu.

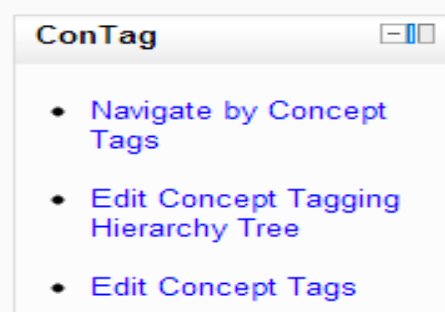

Picture 6: Menu of the concept tag plug-in

This interface leads the educator to create a hierarchy tree of the concepts that comprise the e-course. Easier learning objectives should be on the top of the hierarchy tree. Picture 7 shows an example of a hierarchy tree that represents mathematical concepts.

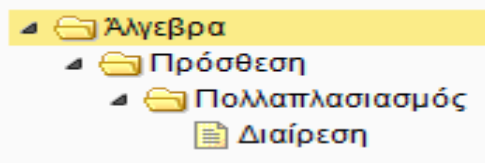

Picture 7: Example of concept tag hierarchy tree

Example of a concept tag hierarchy treeThe «Hierarchy Tree» provides the user the following options:
a) Append a new node
b) Remove a node
c) Collapse the nodes of a sub-tree
d) Rename a node
e) Drag and drop a node

As soon as the educator has created the hierarchy tree, they need to assign the semantics to the resources. In order to achieve that, the educator has to choose "Edit Concept Tags" from the menu. This will lead the educator to the form that is presented in the Picture 8. 


\begin{tabular}{|c|c|c|c|}
\hline Item & Type & Tags applied & Add tags Save \\
\hline News forum & forum & Adyeßpa $[x]$ & k \\
\hline 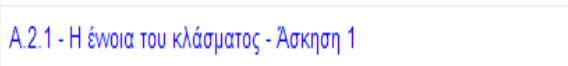 & quiz & & к人áopara \\
\hline 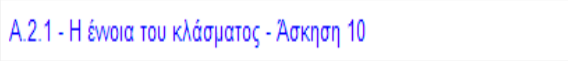 & quiz & & \\
\hline A.2.1 - H Éwola tou kháopatos - Aøкnon 11 & quiz & & \\
\hline
\end{tabular}

Picture 8: Form for attaching concept tags to resources

This form is used from the plug-in "ConTag" (Elmadani, 2012) with expanded functionality in order to serve our purposes. The concepts that were defined earlier in the hierarchy tree are now shown as default tags to the user. The educator may also decide to add new concepts that will automatically be added to hierarchy tree. These concepts are added without hierarchical information, so the educator needs to go back, and move the node to the appropriate position within the tree. The educator can also erase the link between the concepts and resources, by clicking the $\mathrm{X}$ next to the tag on the "Tags Applied"' column.

The last offered feature is the «Navigate by Concept Tags» which is available on both students and educators. This feature was already available in the "ConTag» plug-in and it presents the resources grouped by the concepts that they are linked to.

\section{Conclusions and future work}

In this paper we have described a software solution of a learner-centric environment. For purposes of demonstration, the environment uses the learning material of Greek Secondary School Mathematics $\left(1^{\text {st }}\right.$ grade) as it is presented in the digital book of Mathematics published from the Hellenic Ministry of Education and Religious Affairs, Culture and Sports. The e-learning material is expanded in order to exploit the advantages of e-learning 2.0, thus the final environment contains: pages, quizes, forums, user tracking, user feedback, and multimedia elements.

The system uses Moodle LMS for its base. We have focused on expanding the Moodle functionality by creating new features through expanding the plug-in "Contag" (Elmadani, 2012). The features are implemented with the usage of Web Service technologies, so it will be possible for other platforms to use this functionality. More specifically, the features we are proposing are helping the educator construct hierarchical structure of the course's learning objectives. The system in turn, will use this knowledge in order to provide personalized guidance according to the user's actions in the system.

The environment described above is still under construction. This means that there are still features that need to be implemented and plans for adding new functionalities. These plans include a further exploitation of e-learning 2.0 with the addition of wiki, forum, chat, extra activities and concept maps. Concerning the adaptive functionalities we intend to implement the adaptive navigation feature for the student that will contain the features of adaptive feedback, completion tracking, and dynamic quiz navigation as described above. When the system is ready, it is already agreed that it will be used by students of the "Experimental Secondary School of Heraklion"' in Crete in order to evaluate it and suggest further changes. The evaluation method will be based on TAM (Davis, 1986) tool, as it is the most widely accepted by researchers (Psycharis et al., 2013). Our ultimate goal is to demonstrate a complete solution of an 
e-course that exploits Moodle LMS functionalities and embraces learner-centric and collaborative learning, and to bring Moodle LMS one step closer to adaptivity.

\section{References}

Anderson, T. (2004). The Theory and Practice of Online Learning. Canada: Athabasca University Press.

Annan N.-P. (2013). Adaptive Web Based Application Development. International Journal of Engineering and Computer Science (IJECS), 2(3) 650 - 657.

Aydin, C., \& Tirkes, G. (2010). Open source learning management systems in distance learning. Turkish Online Journal of Educational Technology, (9)2 175-184.

Bartolome, A. (2008). Web 2.0 and New Learning Paradigms. eLearning Papers No. 8.

Caladine, R. (2008). Enhancing eLearning with media-rich content and interactions. Hershey: Information Science Pub.

Chaka, C. (2010). E-Learning 2.0: Web 2.0, the Semantic Web and the Power of Collective Intelligence in Yang, H. H., \& Yuen, S. C.-Y. (Eds.). Handbook of research on practices and outcomes in e-learning: Issues and trends. Hershey, PA: Information Science Reference.

Chen, S. (2002). A Cognitive Model for Non-Linear Learning in Hypermedia Programmes. British Journal of Educational Technology, 33(4), 449-60.

Cheng, I. (2010). Multimedia in education: Adaptive learning and testing. Singapore: World Scientific.

Conde, M.-A., García, F.-J., Alier, M., \& Casany, M.-J.(2011). Merging Learning Management Systems and Personal Learning Environments. Paper presented at The PLE Conference, Southampton, UK.

Cummins, J., Brown, K., \& Sayers, D. (2007). Literacy, technology, and diversity: Teaching for success in changing times. Boston, MA: Pearson

Davis, F. D. (1986). A technology acceptance model for empirically testing new end-user information systems: Theory and results, Doctoral Dissertation, Cambridge-MA: MIT, Sloan School of Management.

Despotovic-Zrakic, M., Markovic, A., Bogdanovic, Z., Barac, D., \& Krco, S. (2012). Providing Adaptivity in Moodle LMS Courses. Educational Technology \& Society, 15(1), 326-338.

Ellis, R.-D., \& Kurniawan, S.-H. (2000). Increasing the usability of online information for older users. A case study in participatory design. International Journal of Human-Computer Interaction, 12 (2) 263-276.

Elmadani, M., Mathews, M., \& Mitrovic, A. (2012). Concept tagging in Moodle. Paper presented at the 1st Moodle Research Conference, Heraklion, Greece.

Exter, K., Rowe, S., Boyd, W., \& Lloyd, D. (2012). Using Web 2.0 Technologies for Collaborative Learning in Distance Education-Case Studies from an Australian University. Future Internet, 4(1), 216-237.

Goodyear, P., \& Retalis, S. (2010). Technology-enhanced learning: Design patterns and pattern languages. Rotterdam: Sense Publishers.

Harper, D. G., \& Hirtz, S. (2008).Education for a digital world: Advice, guidelines, and effective practice from around the globe. Vancouver: Commonwealth of Learning.

La Trobe University (n.d.) Gagne's 9 steps of instruction. Retrieved from http://tlweb.latrobe.edu.au/education/learning-materials/lessonplanning/lessonplanning080.html

Mohawk College. (2009). Final report of the LMS project. Retrieved from http:// lmsreview.mohawkcollege.ca/docs/LMSreviewFinalReport_ModifiedBrief.pdf

Monarch Media, Inc. (2010). Open-Source Learning Management Systems: Sakai and Moodle. Business White paper: Retrieved July, 11, 2012 from http://www.monarchmedia.com/enewsletter_2010-3/open-source-lms-sakai-and-moodle.pdf

Naidu, S. (2003). E-Learning: A guidebook to principles, procedures and practices. New Delhi: Commonwealth Educational Media Centre for Asia.

O' Reilly, T. (2005). What is Web 2.0. - Designing Patterns and Business Models for the Next Generation of Software. Retrieved http://www.oreillynet.com/pub/a/oreilly/tim/news/2005/09/30/what-is-web-20.html

O' Reilly, T., \& Battele, J. (2009). Web Squared: Web 2.0 Five years on. Retrieved from http://www.web2summit.com/web2009/public/schedule/detail/10194

Ohler, J. (2008). The Semantic Web in Education. Educause Quarterly, 31(4), 7-9. 
Paramythis, A., \& Loidl-Reisigner, S. (2004). Adaptive Learning Environments and e-Learning Standards. Electronic Journal of e-Learning, 2(1), 181-194.

Psycharis, S., Chalatzoglidis, G., \& Kalogiannakis, M. (February 01, 2013). Moodle as a learning environment in promoting conceptual understanding for secondary school students. Eurasia Journal of Mathematics, Science and Technology Education, 9(1), 11-21.

Reddi, U. V., \& Mishra, S. (2003). Educational multimedia: A handbook for teacher-developers. New Delhi: Commonwealth Educational Media Centre for Asia.

Redecker, C., \& Punie, Y. (2010). Learning 2.0 Promoting Innovation in Formal Education and Training in Europe. Lecture Notes in Computer Science, 6383, 308-323.

Ryann, E. (2009). A field guide to Learning Management Systems, American Society for Training and Development.

Retrieved

from http://cgit.nutn.edu.tw:8080/cgit/PaperDL/hclin_091027163029.PDF

Taylor, J. C., \& Australia (2001). Fifth generation distance education. Canberra: Higher Education Division, Dept. of Education, Training and Youth Affairs.

Warschauer, M. (2011). Learning in the cloud: How (and why) to transform schools with digital media. New York: Teachers College Press.

World Wide Web Consortium (W3C) (2007). Semantic Web. Retrieved from http://www.w3.org/2001/sw/. 